\title{
EL EBOOK BUSCA EN LA LECTURA SOCIAL LA PROPUESTA QUE IMPULSE NUEVOS FORMATOS DE ÉXITO
}

\author{
Berta García Orosa* \\ Facultad de Ciencias de la Comunicación. Universidad de Santiago de Compostela. \\ Xosé López García ${ }^{* *}$ \\ Facultad de Ciencias de la Comunicación. Universidad de Santiago de Compostela.
}

\begin{abstract}
Resumen: Los datos recientes señalan un punto de inflexión en la evolución creciente de la lectura digital que invita a la reflexión crítica. Según los últimos datos publicados, la edición de libros electrónicos se ha reducido por segundo año consecutivo en 2014 mientras que la producción libros de papel se ha incrementado (MECD, 2015). Al mismo tiempo, el último informe de la Fundación Telefónica (2015) indica que seis de cada diez españoles prefieren los libros impresos a los digitales. Este artículo expone los síntomas de un posible cambio de tendencia en los libros digitales y postula la necesaria creación de un nuevo ecosistema digital de producción y recepción de textos digitales en el que la lectura social destaca como espacio de lectura, de interpretación y de creación de conocimiento.
\end{abstract}

Palabras clave: Libro digital; lectura social; interactividad; internet; transmedia; web 2.0.

Title: DIGITAL BOOKS RELY ON SOCIAL READING TO FIND NEW SUCCESS PROPOSALS AND FORMATS

Abstract: Digital reading development has reached turning point. In view of the recent data, the edition of electronic books has dropped for the second consecutive year in 2014, while paper books production has increased (MECD, 2015). The last report from the Fundación Telefónica (2015) points out that six out ten Spanish people prefer printed books instead of the digital ones. This article presents the symptoms of a possible change of tendency in digital books. There is a need for a new digital ecosystem of digital texts production and reception. Its major focus should be the social reading, understood as a space for reception, interpretation, and creation.

Keywords: Digital book; social reading; interactivity; Internet; transmedia; web 2.0.

\section{INTRODUCCIÓN}

A principios del siglo XXI se auguró que el e-book contribuiría al mayor desarrollo del mundo editorial desde la imprenta (Ziden; Khalid, 2014). Años después, tras un incremento continuado de su mercado y de sus lectores, se concibió como una posible salida de la crisis del sector editorial. Sin embargo, los últimos informes y estadísticas cuestionan el optimismo de esas expectativas creadas (Warren, 2010). La reducción del crecimiento en Estados Unidos o la bajada de la edición de libros en España en los dos últimos años son síntomas de un reajuste de los hábitos de lectura.

La implantación de un nuevo modelo de producción y consumo editorial de la mano de la era digital es incuestionable. No obstante, la forma de ese modelo no es definitiva a pesar de los avances y las nuevas propuestas. Las contradicciones son múltiples: entre ellas, la complejidad de un mundo editorial en el que conviven la economía de libre acceso a textos digitales (especialmente en informes y contenidos académicos) con otros modelos derivados de sistemas de pago por acceso y servicios pero cuya rentabilidad está sujeta a la amenaza de la piratería.

Los informes y trabajos científicos realizados en los últimos años sobre el libro digital ofrecen diferentes valoraciones sobre su dimensión, características y futuro. La ausencia de parámetros homogéneos para la medición e incluso la dificultad de unificar una definición del objeto de análisis al tratarse de un fenómeno en transformación exigen una interpretación cabal del proceso que extraiga las líneas principales de la enorme cantidad de datos disponibles y ofrezca algunas claves para entender el futuro próximo. Este artículo conceptual busca examinar los indicios de cara al futuro del libro digital en un momento en el que se detectan algunos cambios de tendencia y postula como una de las vías de futuro la lectura social. Con este objetivo, se aborda una revisión bibliográfica, la recopilación y el análisis de los informes y estudios presentados en los últimos años sobre el objeto de estudio. A partir de los resultados de este análisis documental, se presenta un breve estado de la cuestión, se revisa la situación en España y, a

\footnotetext{
*bertago@gmail.com

**xose.lopez.garcia@usc.es

Recibido: 16-12-2015; 2 ${ }^{\mathrm{a}}$ versión: 12-05-2016; aceptado: 13-05-2016.
}

GARCÍA OROSA, B. y LÓPEZ GARCÍA, X. El ebook busca en la lectura social la propuesta que impulse nuevos formatos de éxito. Anales de Documentación, 2016, vol. 19, nº 2. Disponible en: http://dx.doi.org/10.6018/analesdoc.19.2.246351. 
continuación, se analiza la posible creación de un nuevo ecosistema digital de lectura que ofrezca al ebook un espacio propio de desarrollo y no como mero sustituto del libro de papel y su propio e inexportable ecosistema.

\section{ESTADO DE LA CUESTIÓN}

Los análisis sobre el libro electrónico son todavía sectoriales y fragmentados y se precisan investigaciones de síntesis (Armstrong; Lonsdale, 2009; Alonso; Cordón; Gómez, 2014). Sin duda, la lectura es diferente en la red, con más mezcla de textos y más diversidad sociocultural, por lo que resulta un entorno más idóneo para practicar la criticidad (Cassany, 2011, p. 31). Este contexto de lectura al que hacía referencia Cassany se construyó a través de libros digitales y su definición se fue adaptando a la propia evolución tecnológica.

Ziden y Khalid (2014), indican que el concepto de ebook existe desde la década de los 60 del siglo XX y está todavía buscando una definición única, difícil por ser un fenómeno muy cambiante, flexible y permeable a los contextos. Desde una perspectiva amplia, el ebook puede considerarse una versión digitalizada de un libro para visionarlo sobre un dispositivo electrónico determinado o un fichero en formato digital.

La evolución de las definiciones de libro electrónico caminó de la mano de las innovaciones tecnológicas y de la experimentación en nuevas narrativas y formas de leer. Hoy es mucho más que el texto transmitido a través de un dispositivo electrónico y su significado apunta a la creación de un nuevo espacio de producción y recepción de texto.

Como indica Rideout (2014) su historia podría iniciarse con los libros electrónicos para niños: libros de cuentos que zumbaban o emitían pitidos al presionar un botón. A continuación, aparecieron los libros electrónicos de aprendizaje, elementos como LeapPads que fueron diseñados específicamente para ayudar con la alfabetización temprana mediante la lectura de las palabras en voz alta a los niños, ayudándoles a pronunciar o definir las palabras. Después fue la lectura en línea: la migración de ciertas plataformas de impresión, como revistas y periódicos, a las pantallas de ordenador.

Finalmente, el desarrollo de libros electrónicos dedicados como el Kindle y el Nook, pequeños dispositivos móviles polivalentes tales como teléfonos inteligentes y iPod Touch, y las tabletas como el iPad. Si bien en un inicio los libros electrónicos utilizaban la tecnología únicamente como transmisión del libro originariamente concebido para el papel, la mejora de la portabilidad, la búsqueda y acceso (Warren, 2010, p. 39), junto a plataformas de lectura en las que se desarrollan nuevos formatos y narrativas específicas para la web, marcan una caracterización específica.

Se advierte, por tanto, una brecha entre los libros pensados para el papel que utilizan únicamente el dispositivo electrónico como una vía de comunicación pero con apenas cambios en la forma de diseñar el texto, y aquellos otros concebidos y transmitidos a través de la tecnología digital aprovechando algunas o varias de las opciones que ofrece. Frente al libro electrónico como una imagen digitalizada de un producto de papel, emerge el formato electrónico como un dispositivo que amplía y transforma el esquema de publicación en la era digital (Warren, 2009).

Las ventajas del libro electrónico responden a las nuevas oportunidades tecnológicas como podemos observar en la Tabla I con un acceso más amplio y flexible a contenidos ofrecidos a través de nuevas narrativas y soportes. Sus inconvenientes proceden de la incompatibilidad de los lectores de diferentes empresas y los formatos de los libros ( $p d f$, epub, mobi, $f b 2$, etc.). Inicialmente, el usuario leía los textos digitales fundamentalmente a través de la pantalla del ordenador debido al limitado acceso a otros dispositivos de lectura. En los últimos años, se han resuelto algunos de estos inconvenientes (lectores digitales en tinta electrónica, tabletas, móviles inteligentes, etc.) y los libros electrónicos están emergiendo como la última frontera que editores, bibliotecas y centros traspasan para lograr un objeto multiplataforma y multidispositivo (Alonso; Cordón; Gómez, 2014). 


\begin{tabular}{|l|}
\hline Ventajas \\
\hline Accesibilidad y accesos múltiples simultáneos \\
\hline Portabilidad \\
\hline Nuevos formatos \\
\hline Acceso a más contenidos \\
\hline Posibilidad de interactividad \\
\hline Integración de libros / revistas en plataforma única \\
\hline Mayor seguridad, la reducción de la pérdida de libro / daños \\
\hline $\begin{array}{l}\text { Costo y ahorro de tiempo (por ejemplo, la manipulación física y } \\
\text { procesamiento, pero no en marketing) }\end{array}$ \\
\hline Mejor relación calidad - precio para el presupuesto de adquisición \\
\hline Usabilidad \\
\hline Inmediatez de la consulta \\
\hline Actualización \\
\hline Capacidad de almacenamiento \\
\hline Permite el uso de estadísticas \\
\hline Facilita la lectura social \\
\hline Navegabilidad y posibilidades de recuperación de información \\
\hline
\end{tabular}

Tabla I. Principales ventajas e inconvenientes de los libros digitales. Fuente: elaboración propia.

La menor oferta de contenidos por parte de las editoriales y la incompatibilidad de formatos de recepción, son dos aspectos que se han ido solventando paulatinamente pero el libro digital debe también combatir en los próximos años un fenómeno facilitado por la red: la piratería. En total, durante 2014 se tuvo acceso ilegalmente a 4.455 millones de contenidos digitales, con un valor de mercado de 23.265 millones de euros según el observatorio de la piratería de la Federación de gremios de editores de España. De estos, el 11\% eran libros con un total de 335 millones de accesos ilegales con un valor de mercado de 2.680 millones de euros. Los editores indican, pese a la situación grave, que los datos se redujeron levemente en el último año.

A estas cuestiones técnicas y legales que se van solucionando paulatinamente, se unen las investigaciones que indican las dificultades de comprensión y lectura en los libros digitales. Mangen y Kuiken (2014) y Mangen, Walgermo y Kolbjønnick (2013) realizan una revisión de los últimos estudios comparativos sobre lectura en impreso y en digital e indican que son abundantes las investigaciones que aseguran que la lectura de textos lineales largos en pantalla puede impedir los procesos de alto nivel subyacentes a la comprensión, la metacognición y el recuerdo. Mangen; van der Weel (2015) justifican la contribución marginal de las novelas hipertextuales como destinadas a un público específico.

Frente a estas dificultades, obstáculos o elementos que marcan el techo de lectores de ebooks, se celebran ventajas $\mathrm{y}$, sobre todo, potencialidades que se sustancian progresivamente en su desarrollo. Aunque la evolución cuantitativa en el libro digital en Estados Unidos - con Reino Unido un mercado de referencia para el libro electrónico-, es diferente en España, las tendencias de crecimiento y usos son paralelos (Alonso; Cordón; Gómez, 2014). Pese a que la lectura de libros impresos continúa siendo abrumadoramente mayoritaria frente a la digital, la evolución y el crecimiento de la segunda es importante y continuada. En España, igual que en Estados Unidos los lectores digitales superan a los lectores impresos. Sin embargo, si diferenciamos los lectores de libros y los que lo hacen sobre dispositivos no dedicados, entonces las cifras se inclinan claramente hacia la lectura impresa, si bien la lectura digital va teniendo un crecimiento continuado y sostenido (Alonso; Cordón; Gómez, 2014, p. 13-14). A uno y otro lado del Atlántico el lector digital es un lector intensivo, multiformato, multidispositivo, que lee más que el que solo lee en papel. Se abre, por tanto, un gran espacio de lectura y, sobre todo, de comunicación.

\section{EVOLUCIÓN DEL SECTOR EN ESPAÑA}

El libro digital registró, desde el inicio, un continuado incremento en casi todos sus indicadores e incluso se vislumbró como posible salida de la crisis que afectó al sector editorial en los últimos cinco años. Esta tendencia, en cambio, se está viendo ralentizada en los dos últimos años. Las cifras sobre la edición y consumo de libros dibujan indicios de un punto de inflexión en el que las editoriales parecen haber alcanzado su techo de producción del libro digital en su concepción actual y experimentan nuevas fórmulas y formatos, mientras incrementan su facturación y edición de libros en papel. El sector editorial se empieza a recuperar gracias al incremento de las ventas de los libros de texto, de temática infantil y juvenil, los científico-técnicos y universitarios, así como el incremento de la 
facturación de los libros digitales (Federación de gremios de editores de España, 2015). Desglosaremos a continuación brevemente este panorama.

La edición de libros digitales ha registrado en 2014 un descenso del 3,1\% respecto al año anterior y supone el $24,6 \%$ de los ISBN inscritos en el año. Los libros electrónicos descienden el 1,9\% y representan el 90,4\% de la edición en otros soportes y el 22,3\% del total de la producción según el avance de Panorámica de la edición española de libros de 2014 publicada por el Ministerio de Educación, Cultura y Deporte. La bajada en el número de libros digitales publicados se hace extensible en el informe al peso de la edición digital sobre el global, que retrocede del $23,2 \%$ en 2013 al 22,3\% el pasado año (MECD, 2015, p. 40-41).

Este descenso en la producción se registra en un año en el que las cifras generales para la producción editorial son positivas (aumentó un 1,9\% en relación con el año 2013) y en el que la edición de libros en papel también se incrementa un 3,7\% (68.378 libros editados en 2014, frente a los 65.942 del año anterior). Así, el libro en papel supone el 75,3\% sobre el total editado y crece por primera vez en los últimos cinco años. Sin embargo, respecto al año 2009 la edición de libros en este soporte registra un descenso del 29,5\%, bajada muy superior a la experimentada por el total de la edición (-17,6\%) (MECD, 2015, p. 16).

\begin{tabular}{|l|l|l|l|l|l|l|l|l|}
\hline & 2008 & 2009 & 2010 & 2011 & 2012 & 2013 & 2014 & Variación \\
\hline Libros digitales & 2.519 & 5.077 & 12.948 & 18.339 & 20.708 & 20.655 & 20.263 & $-1,9$ \\
\hline $\begin{array}{l}\text { Representación } \\
\text { sobre el total }\end{array}$ & 2,4 & 4,6 & 11,3 & 16,4 & 19,8 & 23,2 & 22,3 & $-0,9$ puntos \\
\hline
\end{tabular}

Tabla II. Producción de libros digitales 2008-2014. Fuente: Panorámica de la edición española de libros. Avance 2014.

El descenso del número de ediciones está unido también a la reducción del número de editoriales que publican en este formato. Se modifican los sectores en los que se publica en libro digital y se mantienen o se incrementan los otros indicadores por lo que se podría tratar de un reajuste a favor de una mayor adaptación del formato y contenido a las exigencias de la tecnología y de los nuevos consumidores que permita sobrepasar el techo de edición alcanzado.

La facturación continúa siendo reducida pero con un incremento continuado que alcanza en los últimos cuatro años el 13,9\% (MECD, 2015, p. 43). Según el "Informe del comercio interior del libro 2013", la facturación del libro digital en España alcanzó el pasado ejercicio los 80,3 millones de euro, mostrando en el último año un incremento del 8,1\%.

Al mismo tiempo, se consolidan los ámbitos de especialización del libro digital con un 44,2\% de la facturación de los libros digitales $-48,67$ millones de euros- que corresponde a libros de Ciencias Sociales y Humanas, fundamentalmente libros y bases de datos de Derecho. Los libros de texto no universitario facturaron 24,61 millones de euros, el 22,4\% del total. Los títulos de literatura representaron el 17\% de la facturación total, 18,65 millones de euros, mientras que los de literatura infantil y juvenil tuvieron unas ventas de 3,8 millones, 3,5\% del total, con un descenso de su facturación con respecto a 2013 según la Federación de gremios de editores de España.

Cuatro de cada diez españoles prefieren los libros digitales a los impresos (Fundación Telefónica, 2015) y diseñan un perfil de lector específico en cuanto a temáticas y tendente a la interacción con el propio texto. En esta idea redunda el formato y los dispositivos de lectura. En el primer caso, el formato más utilizado en España es $e P u b$ frente a $P D F$ que permite una lectura más social.

En el segundo, los dispositivos de lectura para los que comercializan inicialmente las obras digitales son fundamentalmente el streaming o la lectura en internet que sube considerablemente hasta el 48,6\% en 2013 (en 2011 un $2,3 \%$ ) y la tableta -un 0,8 y supone el $6,1 \%$ del total-; frente a otros dispositivos que bajan como ereader (-16,6\%) y representa el $21,6 \%$ del total; los ordenadores (21,4\% con un $27,8 \%$ menos), los móviles/PDA (en $-0,8 \%$ ) que suponen el 1,0\% del total (MECD, 2015, p. 47).

El perfil del lector digital es el de un hombre, de 14 a 24 años, que vive en un núcleo urbano, con un nivel social medio-alto, con estudios superiores y con un nivel de lectura muy alto (Alonso; Cordón; Gómez, 2014, p. 13-14) que compra ebooks fundamentalmente a través de las plataformas de distribución (80,2\%) (García, 2013).

Mientras las cifras nos sitúan en un momento de, cuanto menos, inflexión, los libros digitales se adaptan en todo su proceso de producción a las características novedosas que deben corresponder a un nuevo formato en sus fases de producción y comercialización (ideación, producción, emisión, recepción, etc.). Es en esta última -conjuntamente con la edición y adaptación a un nuevo formato como es internet- en dónde se ubican una gran parte de las esperanzas, por 
un lado en relación con el marketing y la distribución y difusión viral de los productos y, por otro, por las posibilidades de un cambio importante en la recepción de los contenidos a través de la lectura social.

\section{LA LECTURA SOCIAL COMO FUTURO DEL LIBRO ELECTRÓNICO}

Las cifras y estudios expuestos nos muestran un crecimiento exponencial en los últimos años de la lectura en dispositivos digitales a través de la innovación tecnológica y una moderada adaptación de los textos a la red. Al mismo tiempo, nos presentan un grupo importante de lectores constantes, activos y dispuestos a experimentar nuevas experiencias. Finalmente, exclusivamente en el sector de la industria, algunos indicadores señalan el descenso o, al menos, la ralentización de crecimiento en el mercado del ebook.

Por lo tanto, en los próximos años el libro electrónico debería superar el techo de lectores que parece haber alcanzado a través de dos grandes fortalezas: el perfil de sus usuarios y una gran potencialidad de avances en la red tanto en producción de textos específicos como en el ámbito de la recepción todavía sin explotar.

Para hacer rentable un modelo económico diferente que conviva con la economía de libre acceso a formatos pero también con la piratería, los editores de libros deberían promover nuevas formas de lectura que abrieran espacios de comunicación en los que el lector no fuera un mero receptor letrado sino que pudiera aportar su experiencia e intervenir sobre el texto a la vez que participase en lugares compartidos con otros receptores. Dos indicadores de las cifras de los informes elaborados en España en 2015 son claves para poder entender la necesidad de ese nuevo espacio de comunicación: el éxito del ePub y del streaming o lectura online, como instrumentos que facilitan la interacción y la flexibilidad de los lugares y situaciones de lectura.

Se trata de asumir la creación de un nuevo ecosistema del libro digital diferente en todas las fases de ideación, producción y consumo al anterior. En ocasiones, el ebook buscaba ser un nuevo libro y, por lo tanto, sustituir al anterior. Sin embargo, las actividades de lectura que provienen del antiguo ecosistema del libro impreso -normalmente un único lector ante un libro en papel con los hábitos de lectura y las experiencias acumuladas- son difícilmente sustituibles como reconoció el propio Erik Schmitt, uno de los primeros diseñadores de Kindle (elpais.com, 20 de abril de 2015).

La evolución proviene de la creación de la actual formación de un nuevo ecosistema de producción y consumo de lectura digital en el que ebook es la pieza fundamental con nuevos hábitos, nuevos lectores y construcción de textos colaborativos. El ebook está llamado a ser una pieza importante siempre y cuando se inserte y se adapte a este nuevo ecosistema que le es propio más allá del intento de sustituir al libro impreso en sus propios campos.

Para ello, los nuevos textos deberán estar concebidos desde un inicio como productos digitales y escritos con nuevas narrativas. Es fundamental asumir que el libro digital es, sobre todo, un producto inacabado y dinámico que se modifica con cada actuación del receptor. El lector puede completar el texto, escanearlo, formular búsquedas, insertar marcas, opiniones, anotaciones y disponer del mismo libro y el contenido creado durante su experiencia lectora en diferentes dispositivos. Pero, además, la lectura alcanza la dimensión social con la posibilidad de compartir el libro con otros lectores e, incluso, crear comunidades.

En este sentido, los avances tecnológicos apoyan la creación de espacios para la lectura social. Lejos quedan ya el pequeño desarrollo de inicio de siglo con experiencias como Badosa.ep, Noveles.com, Poscritos.com o Cyberlibros.com con escasa actividad comercial (Gómez-Escalonilla, 2002). En los últimos años, a las redes sociales generalistas como Facebook o Twitter y los repositorios de libros digitales como 24 symbols, se unieron las comunidades específicas de lectores como entrelectores, LibraryThing o Goodreads. En ellas los lectores pueden compartir texto, comentarios, recomendaciones y, a través de un trabajo colaborativo, crear nuevos conocimientos sobre los textos. TheCopia, Wattpad, BookCountry, Scribd, BookPerk, Kobo ReadingLife, JellyBook, Findings, Openmargin o Quote son solo ejemplos de una amplia variedad de plataformas y aplicaciones para compartir publicaciones de sus miembros, difundir el contenido destacado, diferenciarlo e incluir aportaciones propias.

Estas herramientas de lectura social ofrecen un doble nivel de participación. Por una parte, la realización de un perfil de usuario que contenga lecturas, párrafos destacados, notas, reflexiones, elementos multimedia $\mathrm{y}$, en segundo lugar, la posibilidad de compartir todo ese material. Las expectativas creadas sobre la lectura social son muchas pero el camino difícil y algunas experiencias no llegan al final como Readmill que finalizó el 1 de julio de 2015 tras tres años operativo. 
El nuevo espacio de recepción de textos no sólo modificará la producción de contenidos que deben incorporar los elementos que la faciliten y la recepción, sino que influirá también en la organización empresarial que tiene en la difusión digital uno de sus puntos fuertes. Los modelos de negocio más tradicionales como los micropagos por contenidos fraccionados, el pago por consumo en streaming, la suscripción, el freemium-premium, la publicidad insertada o el acceso abierto, conviven hoy con otras fórmulas que buscan nuevas vías de éxito como el bundle, el crowfunding o los P2P-Mooc's (Rojas; Yuste; Vázquez; Celaya, 2014). Sin embargo, independientemente del modelo de negocio, de nuevo, la colaboración con los usuarios a través de redes sociales o de los propios textos de lectura podría propiciar instrumentos de marketing más efectivos que los tradicionales. El valor añadido de estas nuevas fórmulas serán la comprensión y la adaptación a lenguajes y dinámicas nuevas.

\section{IDEAS FINALES}

El estancamiento en la producción y venta de libros electrónicos, el leve incremento de la producción en papel y la consolidación de nuevos perfiles de lectores son síntomas relevantes de un punto de inflexión en la breve historia del ebook. Los datos ofrecidos por los últimos informes apuntan hacia un lector intensivo, multiformato y multidispositivo que exige nuevas experiencias a su lectura en pantalla. Los indicios obtenidos hasta el momento podrían indicar la búsqueda de una mayor participación del receptor en su interacción con el texto ofrecido por las editoriales.

En este sentido, el concepto de lectura social defendido en el artículo implica transformaciones en la producción y en la recepción de libros pero también constituye un arma importante de difusión y promoción de los productos de la industria editorial para la red.

Si el ebook consigue adaptarse a las características del espacio digital se abren grandes vías de negocio que deberán ser analizadas detalladamente por futuras investigaciones. Por el momento, con los informes y datos de los que disponemos hoy podemos vislumbrar en la lectura social, entendida como un nuevo espacio de lectura con dinámicas diferenciadas de la lectura en papel, uno de los elementos fuertes del futuro próximo del libro digital.

\section{BIBLIOGRAFÍA}

ALONSO-ARÉVALO, J.; CORDÓN GARCÍA, J.A. y GÓMEZ DÍAZ, R. Comparación de los hábitos y perfil del lector digital entre Estados Unidos y España. Anales de Documentación, 2014, vol. 17, $\mathrm{n}^{\circ} 1$.

ARMSTRONG, C. y LONSDALE, R. Establishing methods for future studies on the impact of e-books Information Automation Limited. London: JISC national e-books observatory projects, 2009.

CASSANY, D. Prácticas lectoras democratizadoras. Textos de Didáctica de la Lengua y de la Literatura, 2011, nº 58, p. 29-40.

CORDÓN, J.A. Libros electrónicos: una realidad emergente. Anuario ThinkEPI, 2010, vol. 4, p. 130-138.

FEDERACIÓN DE GREMIOS DE EDITORES ESPAÑOLES. Avance de los resultados del análisis del mercado editorial español en 2014 [en línea]. Disponible en: <http://www.mecd.gob.es/cultura-mecd/dms/mecd/cultura$\mathrm{mecd} /$ areas-cultura/libro/mc/observatoriolect/redirige/destacados/2015/julio/mundo-libro/MercadoLibro2014/Comercio-Interior-del-Libro--Avance-

2014/Comercio\%20Interior\%20del\%20Libro.\%20Avance\%202014.pptx> [Consulta: 7 de diciembre de 2015].

FEDERACIÓN DE GREMIOS DE EDITORES ESPAÑOLES. Informe sobre comercio interior del libro en España [en línea]. Disponible en: $<$ http://www.federacioneditores.org/0_Resources/Documentos/ComercioInterior2013.pdf $>$ [Consulta: 7 de diciembre de 2015].

GARCÍA RODRÍGUEZ, A. El papel de las plataformas de distribución y venta en la promoción del libro electrónico infantil y juvenil. Anales de Documentación, 2013, vol. 16, p. 1.

GÓMEZ-ESCALONILLA, G. El sector editorial de libros: posiciones defensivas frente al reto de las nuevas redes. Revista Telos, 2002, $\mathrm{n}^{\circ} 53$.

JIMÉNEZ, H.; MARTÍN, B. y PALAO, Í. Observatorio de la piratería. Resumen ejecutivo 2014 [en línea]. Disponible en: <http://www.federacioneditores.org/0_Resources/Documentos/Observatoriodepirateria2014.pdf> [Consulta: 7 de diciembre de 2015].

MANGEN, A.; WALGERMO, B. y KOLBJøNNICK, K. Reading linear text on paper versus computer screen: effects on reading comprehension. International Journal of Educational Research, 2013, vol. 58, p. 61-66.

MANGEN, A. y KUIKEN, D. Lost in the iPad: Narrative engagement on paper and tablet. Scientific Study of Literature, 2014, vol. 4, n 2, p. 150-177.

MANGEN, A. y VAN DER WEEL, A. Why don't we read hypertext novels? Forthcoming in Convergence. Convergence: The International Journal of Research into New Media Technologies, 2015, vol. 25, p. 1-16. 
MINISTERIO DE EDUCACIÓN, CULTURA Y DEPORTE. El sector del libro en España 2013-2015. Madrid: Observatorio de la Lectura y el Libro, 2015. Disponible en: <http://www.mecd.gob.es/dms/mecd/cultura$\mathrm{mecd} /$ areas-cultura/libro/mc/observatoriolect/redirige/estudios-e-informes/elaborados-por-elobservatoriolect/sector-libro-abril2015/sector-libro-abril2015.pdf $>$ [Consulta: 7 de diciembre de 2015].

MINISTERIO DE EDUCACIÓN, CULTURA Y DEPORTE. Panorámica de la edición española de libros 2014 , 2015. Disponible en: <https://sede.educacion.gob.es/publiventa/descarga.action?f_codigo_agc $=14904 \mathrm{C}>$ [Consulta: 7 de diciembre de 2015].

PEREDA, C. El inventor del Kindle lee en papel [en línea]. Disponible en: $<$ http://cultura.elpais.com/cultura/2015/04/17/actualidad/1429298616_978672.html> [Consulta: 7 de diciembre de 2015].

RIDEOUT, V. Children, Teens, and Reading. A Common sense media research brief. San Francisco: Common sense media, 2014.

ROJAS, M.J.; YUSTE, E.; VÁZQUEZ, J.A. y CELAYA, J. Nuevos modelos de negocio en la era digital. Madrid: Dosdoce, 2014.

VV. AA. La Sociedad de la Información en España 2014. Barcelona: Ariel, 2015.

WARREN, J. Innovation and the future of e-books. The International Journal of the book, 2009, vol. 6, n 1, p. 83-93.

WARREN, J. The progression of digital publishing: innovation and the e-volution of e-books. The International Journal of the book, 2010, vol. 7, n 4, p. 37-53.

ZIDEN, A.A. y KHALID, N.K. E-Book As Learning Tool: A Review And Focus For Future Research. The Online Journal of Distance Education and e-Learning, 2014, vol. 2, nº 4, p. 19-33. 